$$
\angle A-S \cup B--96-75
$$

April 16, 1996

To: Diana BUS-5

5-6202

From: Dave Korzekwa, IJANL

(505)665-3170

FAX (505)667-5268

dak@mustang.mst6.lanl.gov

Here is the final report for Corncll contract 7898-K

$$
1 / \text { pages }
$$




\section{DISCLAIMER}

Portions of this document may be illegible in electronic image products. Images are produced from the best available original document. 


\section{DISCLAIMER}

This report was prepared as an account of work sponsored by an agency of the United States Government. Neither the United States Government nor any agency thereof, nor any of their employees, make any warranty, express or implied, or assumes any legal liability or responsibility for the accuracy, completeness, or usefulness of any information, apparatus, product, or process disclosed, or represents that its use would not infringe privately owned rights. Reference herein to any specific commercial product, process, or service by trade name, trademark, manufacturer, or otherwise does not necessarily constitute or imply its endorsement, recommendation, or favoring by the United States Government or any agency thereof. The views and opinions of authors expressed herein do not necessarily state or reflect those of the United States Government or any agency thereof. 


\title{
Implementation of a Friction Modcl in an Eulerian Viscoplastic Formulation for Steady Flow
}

\author{
Paul R. Dawson, \\ Donald E. Boyce
}

April 1, 1996 


\section{Introduction}

The goal of this project was to implement the routincs necessary to use the friction model of Wilson and Korzekwa into the finite elcment amalysis program hickory, in the case of an Eulerian referenco frame. hickory is deformation simulation code based on finite element modeling of viscoplastic: deformation. When using hickory, time-dependent problems are inodeled from a Lagrangian refernce frame; whjlc steady-state problcms are modeled from an Eulcrian refercnce framc. The friction model had bcen implemented in carlier versions of hickory, for use with a Lagrangian reference frame. Additional modifications were required, however, to extend this capability to the case of an Eulerian reference fraruc. That is the subject of this report.

The neccssary modifications were rolated to the time integration of the friction state variables. In the case of a Lagrangian refercnce framc, the inilial values of the friction state variables are given on all relevant boundary segments. Then, as time increases, the matcrial timo derivative is evaluated at all points along the boundary and the state variables are updated indcpendently at cach point. In contrast, the application of an Eulcrian reference frame to sludy a stcady-statc flow requires that each specitied boundary segment be a streamline of the flow. As such, an initial valuc for each state variable must be given at the first point of the strcamline, and subscquent values must be detcrmined from previous valucs by integration along the streamline. Additional routincs were added to hickory to implement the stremmline integration along the boundary.

A plane strain rolling problem was used both to test the implenentation and as a source of comparison among friction models. One may model such a rolling problcm by a stcady flow of material approaching a circular roll, being reduced in thickness along the roll, and leaving the roll with a specificd reduction in thickness. The driving force of the rolling process is the frictional force of the roll pulling material through the contact sone. This makes rolling an ideal test problcm.

\section{The Friction Model}

$\Lambda$ number of friction models arc currently implemerited in hickory. Each friction model relatcs the frictional traction to a number of variables, includ- 
ing the relalive velocity of the contacting bodies. One simple model is the velocity difference model:

$$
\boldsymbol{T}_{\iota}=c\left(\boldsymbol{u}_{\boldsymbol{r}} \cdot \boldsymbol{u}_{w}\right)
$$

where $\boldsymbol{T}_{t}$ is the frictional traction, $\boldsymbol{u}_{r}$ is the roll velocily, $\boldsymbol{u}_{\boldsymbol{w}}$ is the workpiece velocity and $c$ is a material constant. In this case, the frictional traction depends continuously on the workpiece velocity. Furthermore, since hickory is a velocity based code, the model can be implomented implicitly, i.e. the: traction contribution of the workpiece velocity can be incorporalcd directly into the velocity stiffness matrix.

Another simple model is the Coulomb model:

$$
\left|T_{\iota}\right|=c T_{n}
$$

where $\Gamma_{n}$ is the normal component of traction and the direction of $T_{t}$ is opposite that of the rclative velocity. Hcre, the dependence of the frictional traction on the workpiece velocity is not explicitly stated and so must be treated as an cxternal applied force. Numerically, the vclocity-innplicit friction models are more stable when implemented in a velocity based code such as hickory.

The general form of the Korzekwa-Wilson friction model is

$$
\left|T_{t}\right|=c_{m} A
$$

the frictional traction is determined by the fractional contact area, $A$, and a function of the material state, $c_{r n}$. $\Lambda \mathrm{s}$ in the Coulomb model, the direction is opposite that of the velocity difference. 'lhe first implementation of this mockal in hickory treated $c_{m}$ as a constant up to the sign. That implementation was later modified so that $c_{\text {in }}$ depended also on the normal componicnt of uraction, $T_{n}$, making it akin to the Coulomb model. The current implementation treats $c_{m}$ as a continuous function of the velucity difference so as to make it velocity implicit. Nevertheless, the primary featurc of the model, the computation of the fractional contact area, remained the samc.

The matcrial derivative of the fractional contact area is computed from the asperity lay vector. The material boing modelod is considered to have surface asperities aligned in a certain dirccion, and as the deforination proceeds, the aligument direction changes with the surface deformation. If the 
initial lay vector is $a_{0}$, the lay vector at a later time is $a(t)=F(t) a_{n}$, where $\boldsymbol{F}(t)$ is the deformation gradient at time $t$. $F$ salisfics the ordinary differential equation:

$$
\dot{\boldsymbol{F}}=\boldsymbol{L F} \text {, }
$$

where $\boldsymbol{L}$ is the velocity gradient. It follows that the equation for the asperity lay is:

$$
\dot{a}=L a \text {. }
$$

Tho equation is integrated numcrically using a midpoint rule:

$$
a_{n+1}=a_{n}+\frac{1}{2}\left(L_{n} a_{n}+L_{n+1} a_{n+1}\right) \Delta t .
$$

This formula is implicit and so must bo applied ileratively. In an Eulerian reference frame, the time step is determined by the spatial subdivision of the strcamline and the velocity. In hickory, the boundary streamline is first divided into its constitucnt surface elements. Then each surface element is further subdivided into a specilied number of subintervals. Numerical integration then procceds along this refiucment.

Once the asperity lay vector is known, one may form a local coordinate system using the lay vector as the firsl direction. The sccond dircction is taken to lis: on the three-dinnensional surface and perpendicular to the lay direction, and the third direction is taken normal to the surface. In this coordinale system, one may keep track of accumulated strains in the first lwo directions, $\lambda_{1}$ and $\lambda_{2}$. These variables are then used to compute the rate of change in the contact area, $A$. The exact details of the contact area update arc given in the routines provided by Dr. D. A. Korrckwa.

It is also neccssary to compute the normal components of traction at each point on the bomdary. This is done by first compuling the global force: vector and then solving a sel of variational equalions to find an equivalent set of tractions. 'This set of tractions is given in the standard coordinalc system and each component is continmous across surface elcments. Then, for each element, the normal and langential components are cornpuled; noto that this introduces discontinuitics in the tractions across elements, since the clemental normal vectors are discontinuuus. Typically, the tractions computed this way will be noisy and must be smoothed. In our implementation, the tractions are smoothed on each boundary segment independently. First, the: numal and tangential components arc averaged at the surface element boundaries 
to produce a continuous ficld on a given segmeml; then, the highest frequency component of oscillation is removed by orthogonal projection. The resulting tractions still have some noise, but are consistent cnought to use in the friction models.

\section{User Input}

Using the friction model in the Eulorian casc requires the same input as in the Lagrangian but with the addition of one further line specifying the direction of integration along the relevant boundary segments. As in the I a agrangian case, friction models are declared and coustants are specified in the same place. Similarly friction surfaces and initial conditions arc specified as before. However, one mure line must follow the initial values for asperity lay and contact area.

This line contains a list of the boundary segment numbers which require friction state variables, with the sign of the number indicating the direction of integration. A boundary segment given a positive number will be taken in a counterclockwise direction; whereas a boundary segment given a ncgative number will be taken in rlockwise direction. For cxample, if boundary segments five and six require friction state variables, and if the velocity field follows surface five and flows against surface six, one would input the line

$$
5 \quad-6
$$

The order does not matter.

If multiple boundary segments are sperificd, each one is integraled independently, according to the sign of the segnent number, as in the input line abovc, and by the initial values for the friction state variables. A possible cnhancernent of the implementation would be to allow for consecutive scgments with the initial value on a latter scgment being taken from the final value of the preceding segment.

\section{Examples}

A rolling problem provided a good test of the implementation. After transicnts have died out, the how of the metal can be assumed to be steady-state, 
and so can be convenicntly modeled in an Eulerian reference frame. In our sample problem, wo modeled high temperalure rolling of 304 stainless steel using Hart's model lo describe the bulk properties. We modeled the friction using the three models describol earlier.

The mosh boundary wns divided into six segments: the inlet (1); the midroll symmetry plane (2); the oullet (3); the outlet frce surface (4); the roll contact surface (5); the inlct free surface (6). The free surfaces and the inlet had traction-free boundary conditions. On the symmctry plane and the roll conlact surfare we rexuired the condition of no mass flux. Friction boundary conditions were specified on the roll-contact boundary to detcrmine the tangential components of traction. For the Korzekwa-Wilson friction model and the velocity difference model, the Iriction boundary condition was sulficient to drive the problem, and so the outlet was assumcd in be traction free. However, for the Coulomb inodel, it was necessary to prescribe a velocity condition on the outlet so as to produce a driving normal traction on the roll contacl surface; otherwise a zero velocity field would satisfy all the corsitraints.

The: roll surface velocity was given as $1.5 \mathrm{~m} / \mathrm{s}$. For the Coulomb mode], the horizontal component of the outlet velocity was given as $1.6 \mathrm{~m} / \mathrm{s}$, which is consistent with the results of the other models. Typically, the models giv: a vclocity profile slower than the roll speed at the inlet and greater than the roll speed at the oulleb, and with a neutral point, the point where the malerial speed matchess the roll velocity, undor the roll.

Several data sets were run for each friction modcl to cxamine the effects of the friction modcl paramclers on the results. Figurc 1 shows a typical fric:tional traction profile for the velocity difference model, and figure 2 shows a typical profile for the Coulomb model. 'The difference hetween the profilcs stems from the fact that in the velocily difference model, the frictional traction depends continuously on the vclocity; whereas in the Coulomb model, the traction abruptly changess sign al the neutral point. In fact, the current implementation of Coulomb's model uses a smooth scaling function to rernove the discontinuity.

As discussed earlier, the current implementation of the Korzckwa-Wilson friction model also uses a scaling function to climinace abrupt changes in sign, but in this case, the scaling is volocity implicit. In addition, the scaling function takes parameters which make the behavior of the friction model more or less like the velocity difference model. The inpul, parameter. $c_{1}$, is 


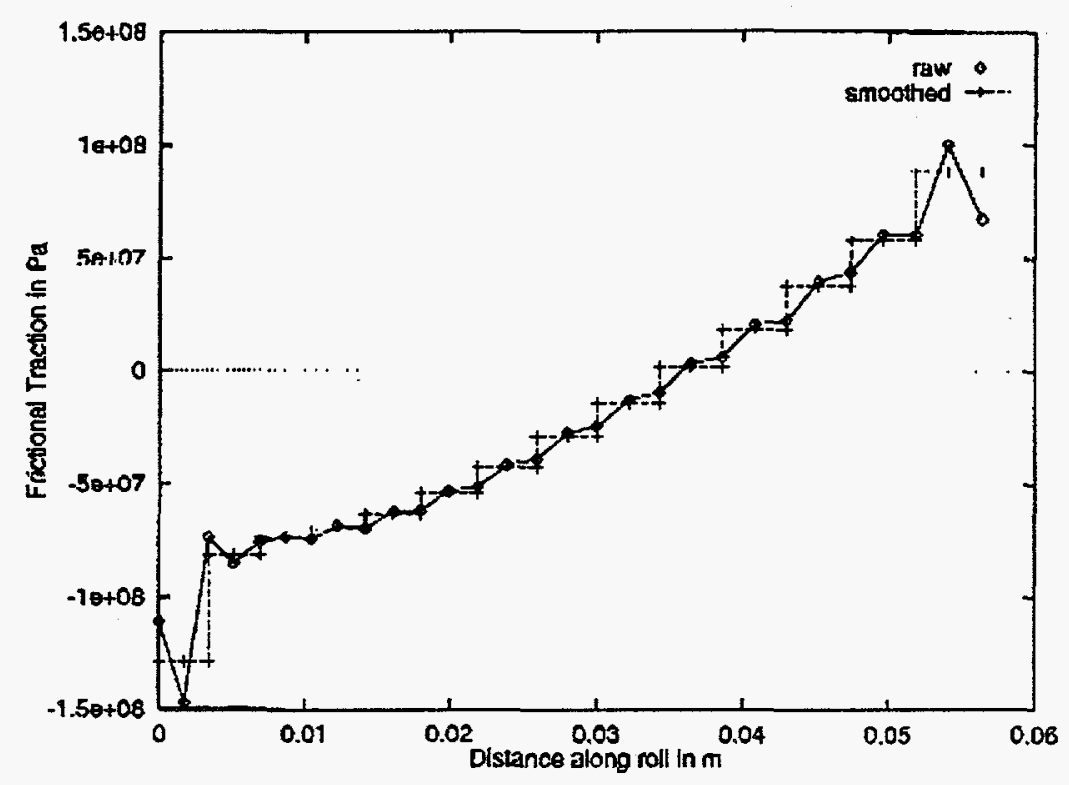

Figure 1: Velocity Difference Model

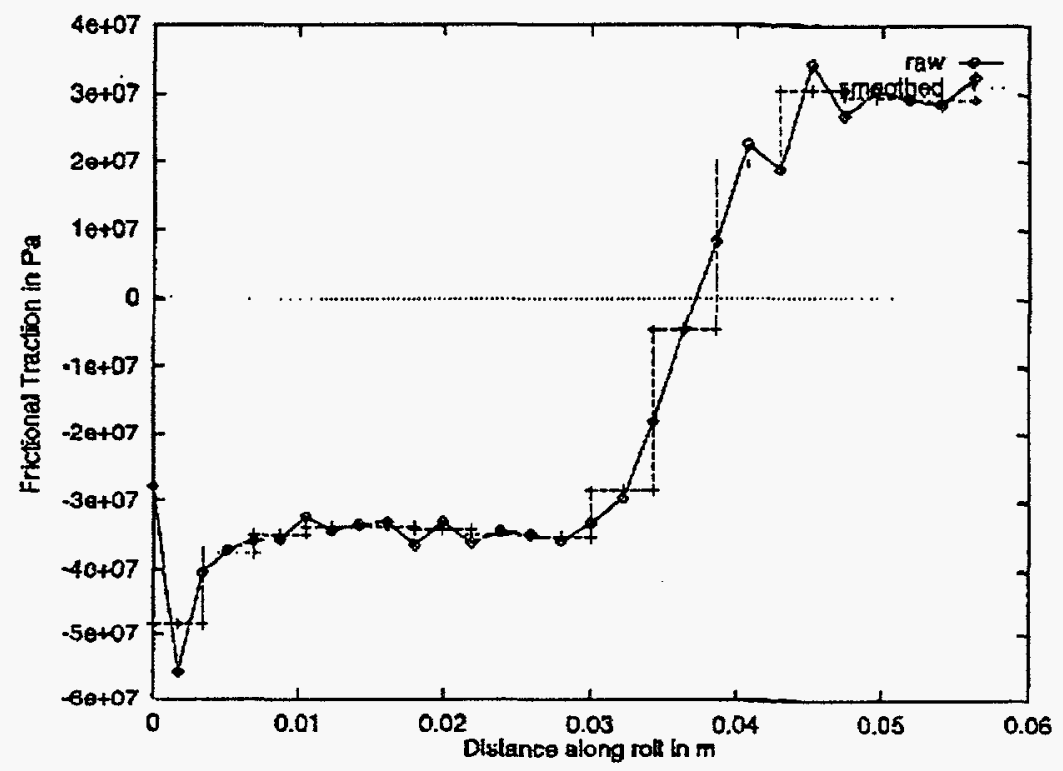

Figure 2: Coulomb Model 




Figure 3: Korzekwa-Wilson friction model $c_{1}=0.1$

a power law type parancter ranging between 0 and 1 . When $c_{1}$ is close to zero, the Korzekwa-Wilson Iriction model behaves more like the Coulomb model, and when $c_{1}$ is near onc, the model behaves more like the velocily difference model. Figures 3 and 4 show the friction traction profiles for the ciss: in which $c_{1}=0.1$ and the case in which $c_{1}=0.8$, respectively.

In the Korzekwa-Wilson friction model, the fratlional coutact area profile is of particular interest. Figure 5 shows the contact arta profiles for three different data scts. The friction coefficient $c_{3}$ was given valucs of $4 \times 10^{7}, 7 \times$ $10^{7}$ and $1 \times 10^{4}$, in all cases the units being $n / \mathrm{m}^{2}$. The typical bohavior is for the contacl arca to saturate rapidly. In the third casc, however, the contact ares never saturalcs bccause the friction coefficient is loo low.

Finally, we should discuss the normal tractions since they are used cxplicitly in both the Coulomb model and the Korzekwa-Wilson friction modes. Figure 6 shows the normal uractions. The normal tractions are somewbat noisy, but gencrally they peak at contact. and diminish until release. Only one value of the normal traction is used per surface element in computing the friction traction. In the current implementation, this value is taken as a weighted average over the surface element nodal points. Figure 6 indicates 


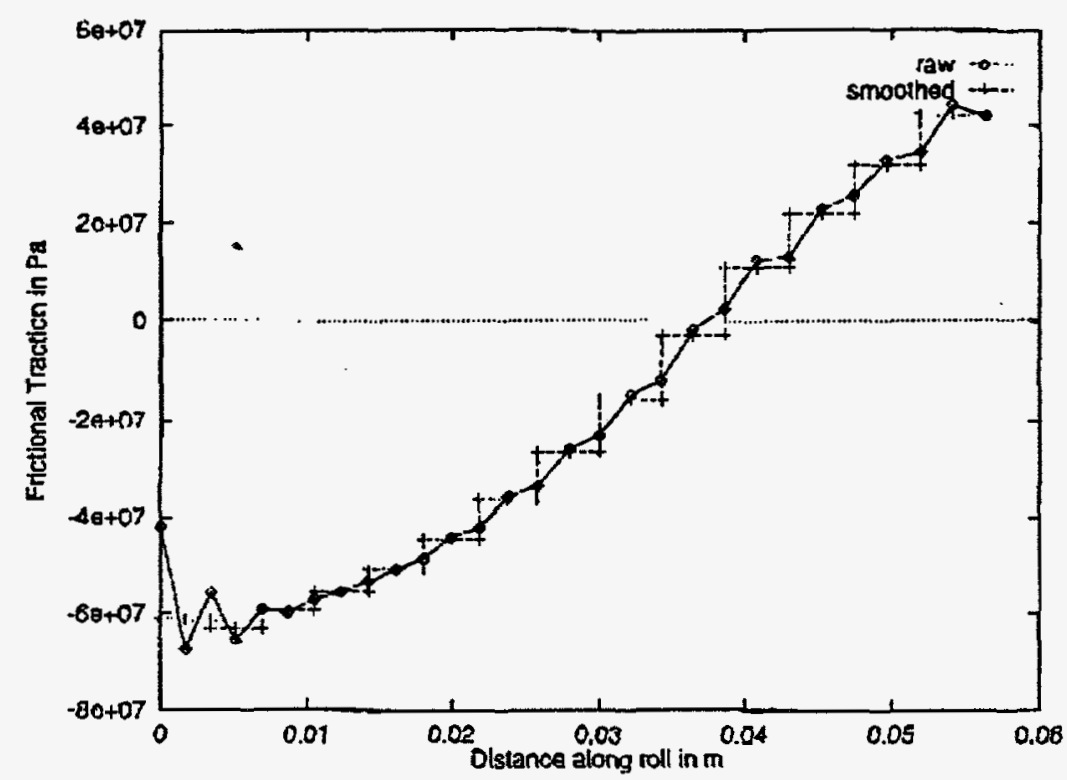

Fignre 4: Korzckwa-Wilson friction model $c_{1}=0.8$

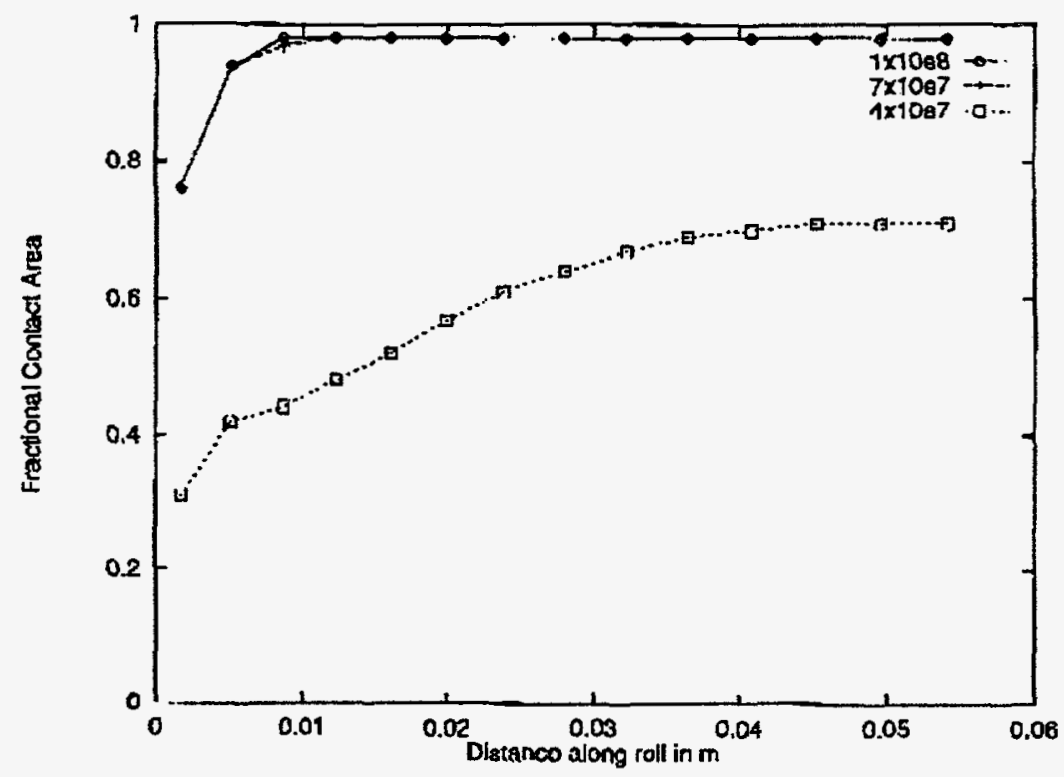

Figure 5: Contact Arca Fraction Along the Roll 


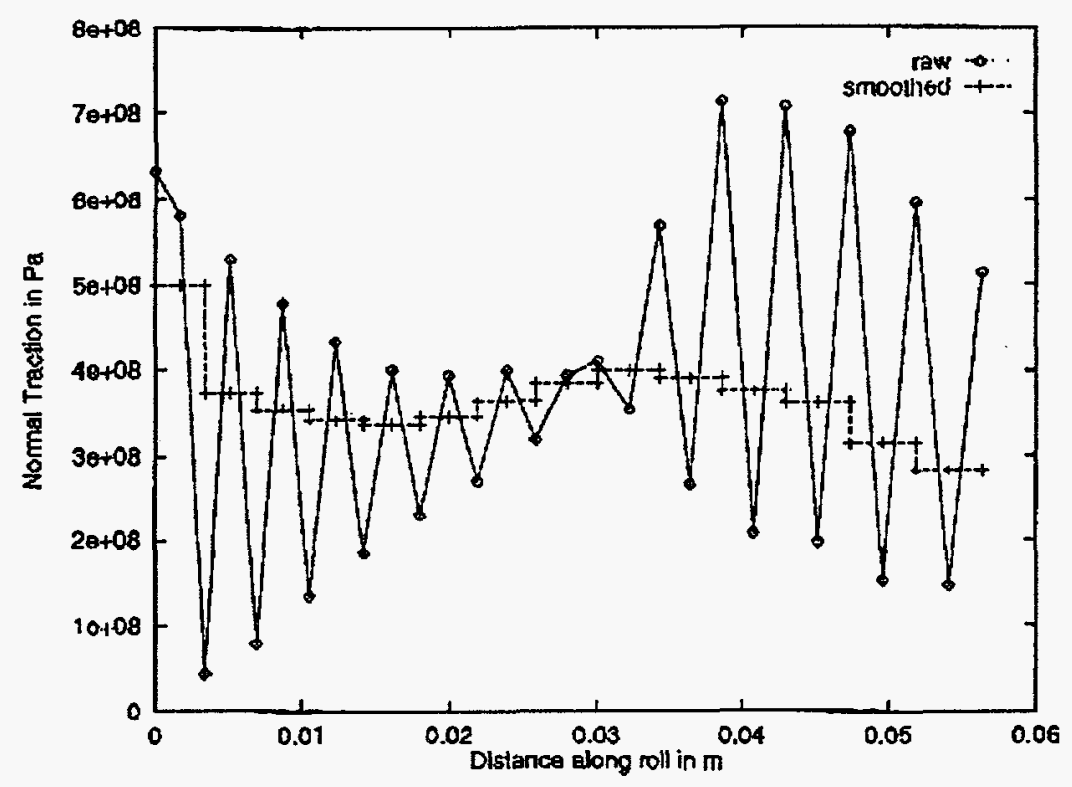

Figure 6: Normal Tractions Along the Rioll

the raw normal tractions as given by the traction recovery algorithm and the smoothed (averaged) normal tractions as used in the friction computation. Even though the raw normal tractions are noisy, the smoothed ones are consistcntly more regular.

\section{Summary}

The friction modeling capability of hickory was exicnded to include the mode:l of Korzekwa and Wilson in the case of an Eulerian reference frame. New routincs werc required which involved integration and update of the friction state variables along segments of the global boundary of the input mesh. The traction evaluation routines were improved to give smoother normal and frictional tractions. A sample rolling problem was run to illustrate features of the currenti implementation. 


\section{Acknowledgments}

This report was funded by Los Alamos National Laboratory under subcontract 3-X63-7898K-1. Discussions with Dr. D. A. Korzekwa proved invaluable and are gratefully acknowledged. 